\title{
Relation between energy use and indoor thermal environment in animal husbandry: a case study
}

\author{
Matteo Bilardo ${ }^{1}$, Lorenzo Comba ${ }^{1}$, Paolo Cornale $^{2}$, Andrea Costantino ${ }^{1,3}$ and Enrico Fabrizio ${ }^{1, *}$ \\ ${ }^{1}$ TEBE Research Group, Department of Energy, Politecnico di Torino, 10129 Torino, Italy \\ ${ }^{2}$ Department of Agricultural, Forest and Food Sciences, University of Torino, 10095 Grugliasco (Torino), Italy \\ ${ }^{3}$ School of Agricultural Engineering and Environment, Universitat Politécnica de Valéncia, 46022 Valencia, Spain
}

\begin{abstract}
Climate control is of the foremost importance in structures for intensive animal rearing because many animals (e.g. pigs and broilers) tolerate a small range of climate conditions (mainly air temperature and relative humidity) that may differ considerably from the outdoor environment. For this reason, the indoor climate in the majority of structures for animal husbandry is guaranteed by HVAC systems. On the one hand, the use of mechanical systems makes it possible to avoid production risks due to the unpredictability of the outdoor weather conditions and to maximize the feed efficiency, with positive effects on both the animal welfare and farm profit. On the other hand, the use of HVAC entails not negligible thermal and electrical energy consumptions. In literature, few data about the real thermo-hygrometric conditions and energy consumption of animal houses are present. In this work (in the framework of the EPAnHaus - Energy Performance certification of Animal Houses - project), the results obtained from a long-term monitoring campaign in two growing-finishing pig houses are presented. The performed measurements concerned environmental parameters and electrical power that were acquired during two production cycles (warm and cool seasons). For the environmental monitoring, both the buildings were equipped with temperature and relative humidity sensors embedded in portable data loggers (10 minutes logging time) that were placed in various spots inside the houses. Outdoor data were obtained through a weather station located near the test site. Concerning the energy monitoring, power transducers connected to portable data loggers (10 seconds logging time) were placed in the electric panel of each house to $\log$ the electrical energy consumptions due to ventilation, lighting and automatic feeding. The acquired data were used for carrying out analysis concerning the indoor thermal environment, its characterization in relation with the animal welfare, the electrical energy uses and the existing relations between all these aspects. The obtained data were used to evaluate the effectiveness of the HVAC system in guaranteeing the adequate indoor climate conditions (avoiding heat/cold stress conditions) and to identify electrical energy uses.
\end{abstract}

\section{Introduction}

Indoor climate conditions inside buildings for animal husbandry (livestock houses) are of foremost importance. An adequate thermal environment inside those buildings assures a high level of animal welfare and the increase of the production (e.g. meat, milk, etc.). For both the purposes, the concept of indoor effective environmental temperature (that embeds various environmental parameters) has been introduced [1] and should be maintained within an adequate range.

Alternatively, instead of the effective environmental temperature, values of indoor air temperature, relative humidity and air velocity for different animal species can be found in literature [1-2]. Those values make it possible to maintain the reared animals within the Thermal Neutral Zone (TNZ), a range of effective environmental temperatures in which the reared animals are able to maintain the homeothermy through chemical and physical regulation, such as piloerection and feed reduction [3]. When the indoor environment is within TNZ, feed efficiency increases because most of the energy provided by intake feed is addressed to the production (e.g. milk or eggs) and growth (meat production) [4].

The limits of the TNZ are the Upper Critical Temperature (UCT) and the Lower Critical Temperature (LCT). When the effective environmental temperature is beyond these limits, animals suffers from heat or cold stress [5-6]. If this stress condition is extended or very intense, hyperthermia or hypothermia risk increases, with negative consequences for the animal health and for the farm production.

To avoid these problems, intensive livestock houses are often equipped with HVAC systems. On the one hand, these systems make it possible to provide the adequate values of the main indoor environmental parameters; on the other hand, they entail a considerable energy consumption. For instance, in pig houses roughly $35 \mathrm{kWh} /\left(\mathrm{m}^{2} \mathrm{y}\right)$ of electricity are needed for ventilation

\footnotetext{
* Corresponding author: enrico.fabrizio@polito.it
} 
and localized heating that is generally provided by electric radiant heat lamps; in broiler houses the thermal energy consumption due to heating can exceed 130 $\mathrm{kWh} /\left(\mathrm{m}^{2} \mathrm{y}\right)[7]$.

\subsection{Aim of the work}

Aim of the present work is to investigate the mutual relationships that exist between indoor climate conditions, energy consumption and animal welfare in animal husbandry. In particular, the case of growingfinishing pig houses is selected and the work falls within a larger project called EPAnHaus (Energy Performance of Animal House, 2014-2017) [8] that was funded by

with the aim of developing a methodology for the energy certification for climate control of livestock houses. In this work, analyses on a dataset that was acquired during a long-term monitoring campaign are performed.

\section{Methodology}

\subsection{The monitored buildings}

In the framework of the EPAnHaus project, a long-term monitoring campaign in two growing-finishing pig houses (in Northwest Italy) was carried out.

The monitoring campaign lasted roughly one year (March 2017 - April 2018) and it was aimed at acquiring data during two production cycles in warm and cool season. The main data of the monitored production cycles (e.g. number of animals and final live weight) are shown in Table 1.

The walls of both the pig houses are made of concrete piled hollow blocks, the rooves of prefabricated sandwich panels and the air inlets of polycarbonate hollow sheets with metal frames. Both the monitored buildings (Pig house A and Pig house B) are characterized by fully slatted floors (reinforced concrete) with slurry pits below. The structural building elements (e.g. slurry pit walls, pillars and beams) are made of reinforced concrete. The main geometrical properties of both the monitored buildings are presented in Table 1.

Both the pig houses are equipped with similar HVAC systems. Heating is provided by two moveable air heaters $(62 \mathrm{~kW}$ each one) that are placed inside the buildings only during the coolest periods. Both the pig houses are equipped with four three-phase direct driven axial extractors with $0.55 \mathrm{~kW}$ of power $(230 / 400 \mathrm{~V}$ at $50 \mathrm{~Hz}$ ). The fans are placed below the pit level for extracting the exhaust air directly from the pits (base ventilation) avoiding the spreading of the contaminants (e.g. $\mathrm{NH}_{3}$ and $\mathrm{H}_{2} \mathrm{~S}$ ) inside the enclosure [1]. The same fans are used to cool the pigs during the warmest periods (cooling ventilation) by increasing the ventilation flow rate (four steps) through a transformer speed controller.
Table 1. Main data of the monitored production cycles and main geometrical properties of the monitored pig huoses.

\begin{tabular}{|c|c|c|c|}
\hline & & $\begin{array}{c}\text { Pig } \\
\text { house A }\end{array}$ & $\begin{array}{c}\text { Pig } \\
\text { house B }\end{array}$ \\
\hline \multirow{3}{*}{ 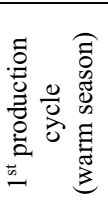 } & Duration & $\begin{array}{c}153 \\
\text { days }\end{array}$ & 160 days \\
\hline & $\begin{array}{c}\text { Number of pigs } \\
\text { (mortality) }\end{array}$ & $\begin{array}{c}155 \\
(3.9 \%)\end{array}$ & $\begin{array}{c}250 \\
(3.6 \%) \\
\end{array}$ \\
\hline & $\begin{array}{l}\text { Weight in } \\
\text { Weight out }\end{array}$ & $\begin{array}{c}25.4 \mathrm{~kg} \\
169.3 \mathrm{~kg}\end{array}$ & $\begin{array}{c}25.1 \mathrm{~kg} \\
170.0 \mathrm{~kg}\end{array}$ \\
\hline \multirow{5}{*}{ 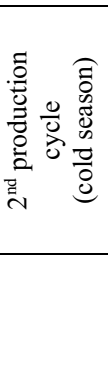 } & Duration & $\begin{array}{c}147 \\
\text { days }\end{array}$ & 159 days \\
\hline & $\begin{array}{c}\text { Number of pigs } \\
\text { (mortality) }\end{array}$ & $\begin{array}{c}155 \\
(0.0 \%) \\
\end{array}$ & $\begin{array}{c}252 \\
(1.2 \%) \\
\end{array}$ \\
\hline & $\begin{array}{l}\text { Weight in } \\
\text { Weight out }\end{array}$ & $\begin{array}{c}28.9 \mathrm{~kg} \\
181.9 \mathrm{~kg}\end{array}$ & $\begin{array}{c}27.3 \mathrm{~kg} \\
184.6 \mathrm{~kg}\end{array}$ \\
\hline & Gross volume & $1400 \mathrm{~m}^{3}$ & $2400 \mathrm{~m}^{3}$ \\
\hline & Gross floor area & $285 \mathrm{~m}^{2}$ & $400 \mathrm{~m}^{2}$ \\
\hline
\end{tabular}

\subsection{The monitoring system}

In both the pig houses, an ad hoc monitoring system was designed and installed, following the criteria of versatility, practicality, robustness and economy. A part of the monitoring system was installed inside the pig houses for the acquisition of the environmental parameters (air temperature and relative humidity) through a network of sensors (thermistors, humistors and resistance temperature detector sensors PT1000) evenly distributed inside the pig houses. The sensors were embedded in portable data loggers with USB communication protocol and all of them were connected through wiring to USB hubs, to make it possible the data download from a single access point per each pig house. The access points were located outside of the buildings for minimizing the risks of health and stress problems for the animals and for avoiding interferences with production tasks. All the devices (sensors, data loggers and USB hub) were protected with corrugated tubes and junction boxes (IP65) to prevent damages that could be caused by the aggressive environment (high presence of dust, humidity and gases), animals and workers.

The other part of the monitoring systems consisted of a $\mathrm{kW}$-transducer for 3-phase systems that was placed in the electrical panel of each house. For technical reasons, a single kilowatt transducer was placed in each electrical panel with the aim of monitoring the total electrical loads. To obtain the partial electrical loads, an ad hoc algorithm for load unbundle and identification was developed [9]. The main features of the monitoring systems are shown in Table 2.

Data concerning outdoor weather conditions were obtained through sensors and data loggers arranged outside of the buildings and third-party weather stations of ARPA (Regional Environmental Protection Agency) Piemonte. 
Table 2. Main features of the monitoring systems that were installed in the pig houses.

\begin{tabular}{|c|c|c|}
\hline $\begin{array}{l}\text { Sensor type } \\
\text { (accuracy) }\end{array}$ & $\begin{array}{c}\text { Pig house } \mathbf{A} \\
\text { (acquisition } \\
\text { time step) }\end{array}$ & $\begin{array}{c}\text { Pig house B } \\
\text { (acquisition } \\
\text { time step) } \\
\end{array}$ \\
\hline $\begin{array}{l}\text { Thermistor } \\
\left( \pm 0.21^{\circ} \mathrm{C}\right)\end{array}$ & $\begin{array}{c}4 \\
\text { (10 minutes) }\end{array}$ & $\begin{array}{c}3 \\
\text { (10 minutes) }\end{array}$ \\
\hline $\begin{array}{l}\text { Humistor } \\
( \pm 2.5 \%)\end{array}$ & $\begin{array}{c}4 \\
\text { (10 minutes) }\end{array}$ & $\begin{array}{c}3 \\
\text { (10 minutes) }\end{array}$ \\
\hline $\begin{array}{c}\text { PT1000 } \\
\left( \pm 0.15^{\circ} \mathrm{C}\right)\end{array}$ & $\begin{array}{c}1 \\
\text { (10 minutes) }\end{array}$ & $\begin{array}{c}2 \\
\text { (10 minutes) }\end{array}$ \\
\hline $\begin{array}{c}\mathrm{kW} \text {-transducer } \\
( \pm 1 \%)\end{array}$ & $\begin{array}{c}1 \\
\text { (10 seconds) }\end{array}$ & $\begin{array}{c}1 \\
(10 \text { seconds })\end{array}$ \\
\hline
\end{tabular}

\section{Results}

\subsection{Analysis of environmental data}

The environmental data acquisition campaign made it possible to measure the temperature of the air inside the two pig houses, as well as the relative humidity.

In Figure 1, the variation of the mean indoor air temperature (obtained as the arithmetic mean among the data acquired) for both the analysed pig houses is shown (blue line for pig house A and orange line for pig house B). The trend of the outdoor air temperature is reported by the black dotted line. The limits of the two production cycles are highlighted by the red dashed lines and between them a sanitary empty period is present. The graph highlights how the internal environmental conditions are different between the first cycle, carried out during the warm season, and the second cycle in the cool season. In the warm season, pigs are subjected to a mean indoor air temperature that often exceeds the value of the outside air temperature. This issue indicates the difficulty in disposing of the excess heat produced by the animals inside the pig house, a symptom of an HVAC system without mechanical cooling that is not able to reduce the internal temperature when outdoor air temperatures are over the ideal air temperature. On the other hand, during the winter months the effect of a thermal regulation is evident, establishing an average air temperature always around $21^{\circ} \mathrm{C}$ which does not depend on the external temperature.

To evaluate the animal welfare in detail and identify the corresponding TNZ, the pig growth was studied. For this purpose, the pig body mass (also called live weight) was expressed as a function of the animal age through the Gompertz function [10], and reads

$$
W(t)=A^{*} e^{-e^{-b^{*}(t-C)}} \quad[\mathrm{kg}]
$$

where $W$ and $t$ are respectively the pig weight and its age (in days), $e$ is the Euler's number and $A, b$ and $C$ are three characteristic parameters evaluated from the curve fitting process on data (of age and weight) that were provided by the farmer. The value of $\mathrm{A}, \mathrm{b}$ and $\mathrm{C}$ that were used in this work are reported in Table 3 for the case study.

Table 3. Gompertz parameters for growing-finishing swine.

\begin{tabular}{|c|c|c|}
\hline $\mathrm{A}$ & $\mathrm{b}$ & $\mathrm{C}$ \\
\hline $\begin{array}{c}\text { Carrying capacity } \\
\text { (maximum weight) }\end{array}$ & $\begin{array}{c}\text { Growing } \\
\text { rate }\end{array}$ & $\begin{array}{c}\text { Starting } \\
\text { age }\end{array}$ \\
\hline 233.86 & 0.0145 & 136.83 \\
\hline
\end{tabular}

Knowing the trend of the weight of the pigs, the ideal set point temperature $t_{\text {id }}$ has been expressed as a function of $W$ through a regression from values that were reported in [11]. This temperature guarantees the animal welfare and growth and it reads

$$
t_{\text {id }}(W)=36.734 * W^{-0.147} \quad\left[{ }^{\circ} \mathrm{C}\right]
$$

The curve described by equation (2) is also shown in Figure 1 by the solid green line. Comparing the value of $t_{\text {id }}$ with the trend of the average air temperature inside the pig houses, there is a marked deviation during the summer production cycle. This temperature difference might induce excessive physiological stress.

To better visualize the thermal comfort conditions, i.e. the TNZ, the UTC and the LCT were evaluated according to the punctual values provided by previous studies [12]. Starting from these values, UCT and LCT curves were extrapolated as a function of weight, fitting the available data to a mathematical law similar to the

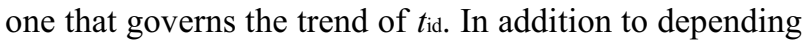
on the weight of the animal, UCT and LCT are also a function of breeding conditions such as floor type, air speed and skin wetness. The two curves are plotted in Figure 1 (red line for UCT and blue line for LCT), while the green area between them represents the TNZ.

Equations (3) and (4) show the two functions extrapolated from the data in the literature to describe the trend of UTC and LCT.

$$
\begin{array}{ll}
\operatorname{UCT}(W)=32.898^{*} W^{-0.056} & {\left[{ }^{\circ} \mathrm{C}\right]} \\
\operatorname{LCT}(W)=33.212^{*} W^{-0.230} & {\left[{ }^{\circ} \mathrm{C}\right]}
\end{array}
$$

From the preliminary analysis of the collected temperature data it is evident that the environmental conditions of the case study do not always fall in the TNZ for pigs. Especially during the warm season, the average air temperature constantly exceeds the value of UCT, inevitably causing discomfort for the animals. In order to quantitatively evaluate the effect of this nonideal thermal condition, the concept of heat-stress index was applied to this case study, as defined by Panagakis [13] using the following equation:

$$
I=\int_{T} \int_{\tau} \Delta T \Delta \tau \quad\left[{ }^{\circ} \mathrm{Ch}\right]
$$




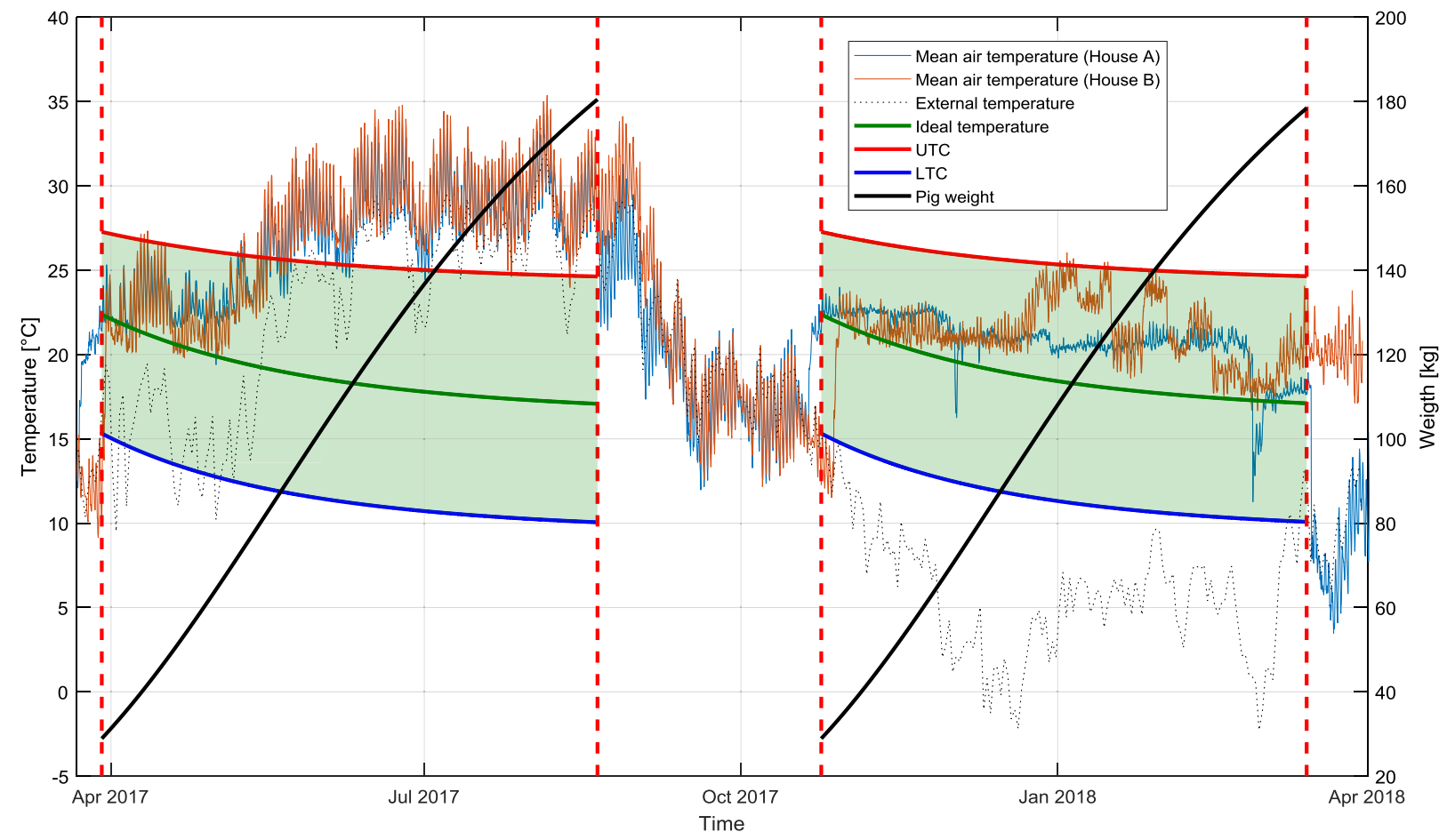

Fig. 1. Air temperature trends, UTC, LCT and TNZ visualization (left axes), pig weight growth (right axes).

where $I$ indicates the heat stress expressed in ${ }^{\circ} \mathrm{Ch}, \Delta T$ is the difference between the average air temperature and the UCT in ${ }^{\circ} \mathrm{C}$ and $\Delta \tau$ is the time in h during which the pigs have been housed at a temperature above the UTC. The value of $I$ therefore provides a quantity useful for estimating heat stress. The $I$-index evaluation was applied to the case study only for the first monitoring period (summer production cycle - P1), which is the most critical period with the highest recorded indoor air temperatures. The results were collected in Figure $2 \mathrm{a}$ (Pig House A) and 2b (Pig House B) and were grouped for each month of the warm season case.

The global seasonal values of the heat stress index $I$ are shown in Table 4.

In addition to temperature, the relative humidity was also monitored for the total duration of the two production cycles. To give a general picture of the two pig houses from the thermohygrometric point of view, the recorded relative humidity is shown in Figure 3 as a function of the associated air temperature. Each point in the figure represents an average hourly value collected during the whole monitoring campaign. Both for pig house A (Figure 3a) and pig house B (Figure 3b) the two production cycles are shown in different colours. While the data representing the summer period (P1) have a greater dispersion in terms of temperature, those relating to the winter cycle (P2) are grouped around a hypothetical set point.

Table 4. Global heat stress index for each production cycle

\begin{tabular}{|l|l|l|}
\hline Facility & P1 & P2 \\
\hline Pig house A & 2251 & 0 \\
\hline Pig house B & 2324 & 23 \\
\hline
\end{tabular}
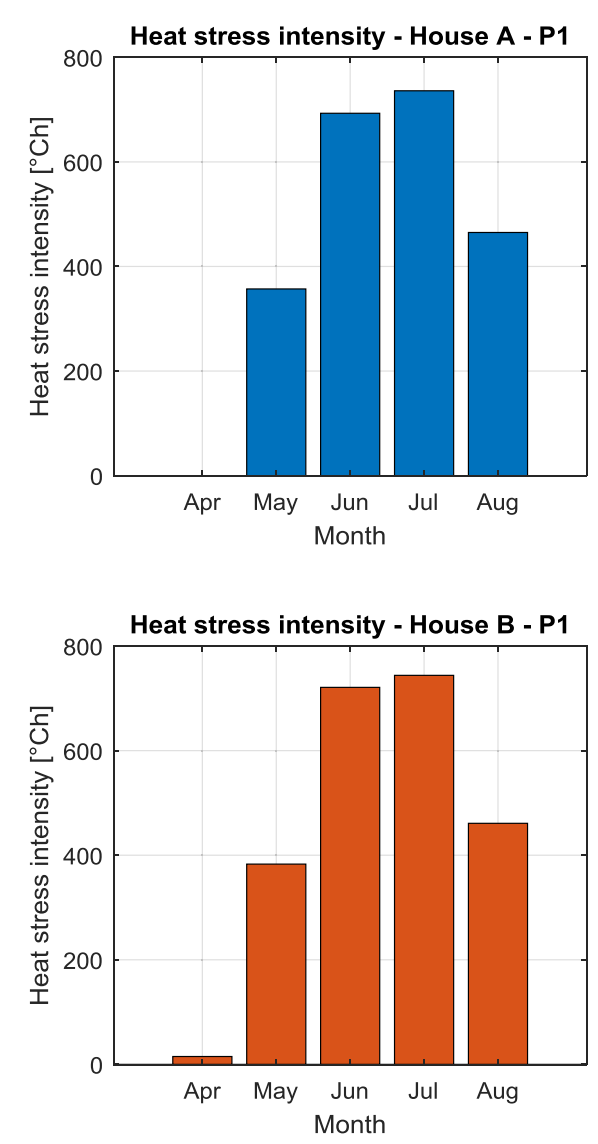

Fig. 2. Monthly heat-stress intensity for Pig House A (a) and B (b) during summer production cycle (P1). 
Compared to what has been presented so far, Figure 3 allows to evaluate the Temperature and Humidity Index (THI), combining the effect of temperature with relative humidity in the environment. In the same figure the areas in which the THI assumes critical values have been represented [14]. These conditions (alert, danger and emergency) suggest that different climate control strategies should be implemented in the actual HVAC system, not being able to provide an ideal environment for the growing process of the pigs. To solve this problem different strategies might be adopted such as the installation of fogging systems or of evaporative pads that are able to decrease the temperature of the inlet air.
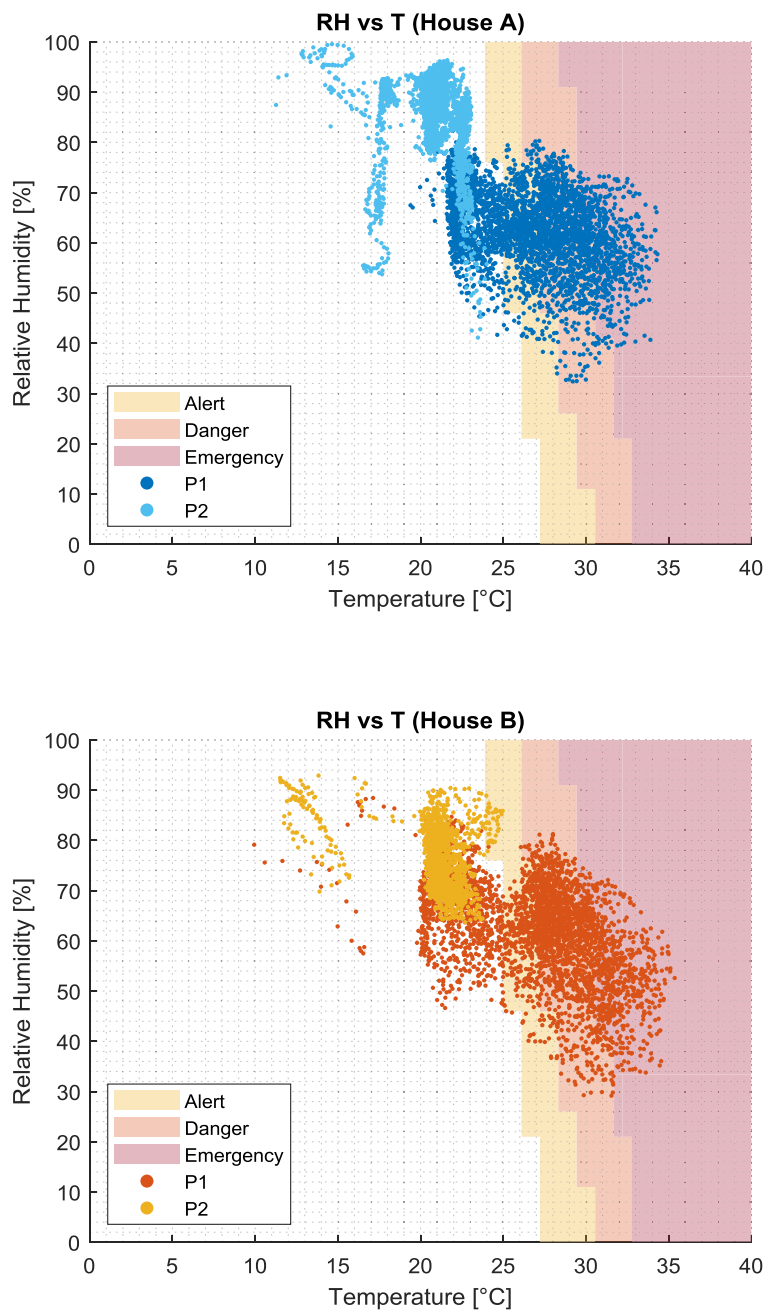

Fig. 3. THI dispersion for Pig House A (a) and B (b) with critical conditions areas.

\subsection{Analysis of energy consumption}

In order to energetically characterize the case study in question, the electrical consumptions of both pig houses were monitored through amperometric clamps. The data collected allowed to evaluate the electric power required by all the users related to the pig houses with a timestep of 10 seconds. For reasons of simplicity and clarity, the data presented here will refer exclusively to pig house A.
The monitoring campaign, although also extended to pig house $\mathrm{B}$, has brought similar results in both facilities. The following comments on the results produced by the data analysis can therefore also be extended to the pig house B.

Since the collected electrical data represent a global value of all the energy uses connected to the production cycle of the pig house, a specific mathematical algorithm has been developed to allow a breakdown of the raw data into three main categories: ventilation, feed distribution and lighting [9]. Other hypothetical electric energy uses have been neglected.

Figure 4 shows the percentage and absolute consumption of the different energy uses for both production cycles (P1 and P2) of pig house A. Despite having a similar percentage distribution, the absolute values demonstrate a lower use of electrical energy during P2 (cycle of winter production), surely due to the minor need for ventilation.

The electricity consumption for both production cycles was subsequently aggregated to evaluate the overall energy consumption of the pig house in relation to the gross floor area and to the kilogram of meat produced. The meat production was assessed by the total weight of the pigs at the end of the production cycle. The total weight has been multiplied by a factor equal to 0.80 , to indicate the useful yield of the total mass usable for economic purposes [7]. Table 5 summarizes the values just mentioned, both referring to individual final energy uses and to total consumption.

Table 5. Global energy consumption over gross area and meat produced.

\begin{tabular}{|l|r|r|r|r|}
\hline $\begin{array}{c}\text { Energy } \\
\text { consumption }\end{array}$ & Ventilation & Food & Light & Total \\
\hline $\begin{array}{l}\text { Per gross floor } \\
\text { area }\left[\mathrm{kWh} / \mathrm{m}^{2}\right]\end{array}$ & 12.88 & 1.08 & 0.56 & 14.52 \\
\hline $\begin{array}{l}\text { Per } \mathrm{kg} \text { of meat } \\
\text { produced } \\
{[\mathrm{Wh} / \mathrm{kg} \text { meat }}\end{array}$ & 55.80 & 4.69 & 2.44 & 62.93 \\
\hline
\end{tabular}

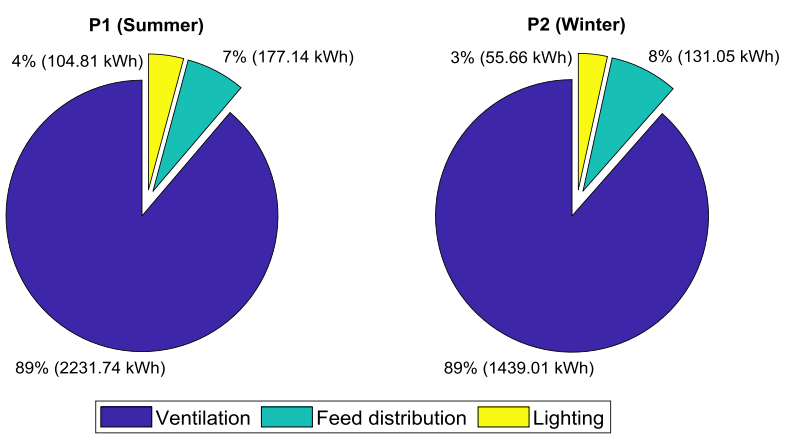

Fig. 4. Total energy share for Pig House A in P1 (a) and P2 (b). 

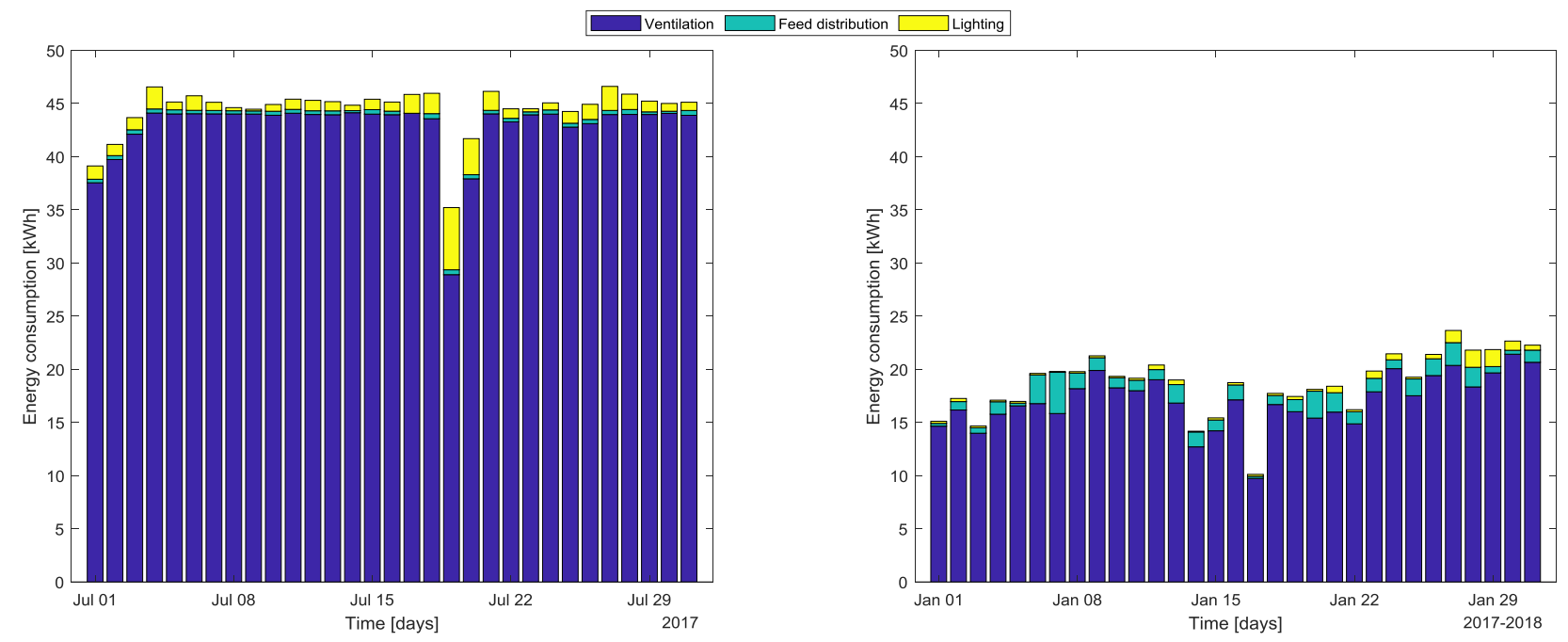

Fig. 5. Energy consumption for Pig House A during a July in P1 (a) and January P2 (b).

To view the typical trend of electricity consumption during production cycles, two typical months were selected for both production periods. Figure 5 shows the subdivision of energy consumption during all the days of the months considered, dividing the total quota into ventilation (blue), feed distribution (light blue) and lighting (yellow). The chosen months are July for the summer period (P1 in Figure 5a) and January for the winter period ( $\mathrm{P} 2$ in Figure $5 \mathrm{~b}$ ). The choice of these specific months, as well as representing typical months belonging to two different seasons, was dictated by the fact that the age of the pigs was similar, although referring to separate production cycles.

The figure compares the daily energy consumption collected for two months belonging to different seasons and production cycles. The results obtained are in accordance with the climatic conditions of the related periods. During summer, to avoid an excessive increase in the internal air temperature, the ventilation system often works at full capacity. This behaviour is confirmed by rather constant energy values during P1. This large amount of energy in not only used to provide the ambient a suitable indoor air quality (IAQ) but also a source of cooling, since no other system is used to reduce the temperature in the pig house.

On the contrary, in the winter month of January the energy consumption is reduced to half with a remarkable decrease of the energy share related to ventilation. In winter, ventilation not only decreases, but is also less constant. This result indicates that in the colder months the HVAC system does not work at maximum power and is only activated to ensure the required fresh air supply. In fact, winter ventilation guarantees a correct value of IAQ, while a specific heating system takes care of the sensitive heating of the environment.

The same figure also includes energy consumption related to feed distribution and lighting, with a significantly lower impact on global energy consumption.
In order to more accurately analyse the energy consumption linked to the feed distribution, the specific electrical energy use were collected in Figure 6. The main axis describes the energy consumption of each hour of the day during the months of July (Figure 6a) and January (Figure 6b). The values shown represent the sum of the hourly electrical energy use during all the days of the month in question. On the secondary axis of both graphs the average hourly trend of the indoor air temperature was reported. Here again, the collected data lead to very different results depending on the period.
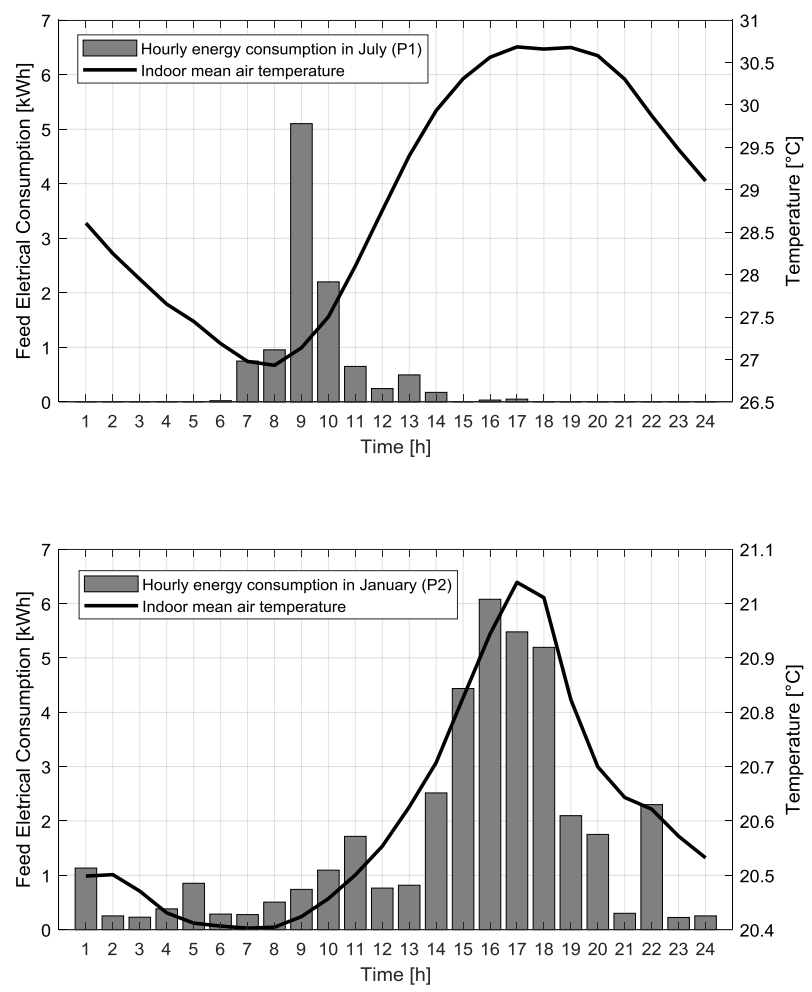

Fig. 6. Relation between electric consumption due to feed distribution and average hourly indoor air temperature during the months of July (a) and January (b). 
In July, almost all consumption connected to the distribution of the feed takes place in the morning, when the internal temperature reaches its minimum, around $27^{\circ} \mathrm{C}$. During the rest of the day the electric consumption is null, while the air temperature increases until reaching a maximum value above $30{ }^{\circ} \mathrm{C}$, not optimal for the thermal comfort of the pigs.

The situation in the winter period is quite different. The consumption related to the feed distribution reaches a maximum value in the afternoon hours, when the internal temperature reaches its maximum of about $21^{\circ} \mathrm{C}$. However, being fed ad libitum, during the rest of the day, consumption is never zero, indicating how the pigs eat more evenly during the day. In this case, the hourly temperature of the indoor air does not undergo large daily variations and is included in the range $20.4-$ $21.1^{\circ} \mathrm{C}$. The lower thermal excursion therefore translates into greater and more distributed energy consumption during the day.

\section{Conclusions}

In this work, the relationships between the indoor environmental conditions, energy consumption and animal welfare were highlighted using as case study two pig houses that were monitored during around one year.

The results showed that in the analysed case study, HVAC systems are able to maintain the adequate indoor climate conditions during almost all the period, with the exclusion of the hottest days during the warm season. During these periods, pigs suffer from heat stress even though HVAC systems provide the maximum ventilation flow rate of outdoor air, as proven by the data from the monitoring system. This situation could be avoided by the installation of evaporative pads to reduce the temperature of the inlet air, and maintain the indoor air temperature within an acceptable range for the animals, also when the outdoor air temperature is over that range. Data showed also that the heat stress affects the animal behaviour: during the hottest periods, pigs are used to feed only during the first hours in the morning (08:0011:00), when indoor air temperature is lower. This behaviour does not promote their growth and the farm production because, being fed ad libitum, pigs could feed during all the day and not only few hours in the morning. The developed monitoring system demonstrated to be versatile and economic; it could be a reliable solution for small, and medium-sized animal farms that are interested in monitor the indoor environmental conditions with a detail outlook on the energy consumption, especially related to the HVAC system operation.

Further works may deeper investigate the relation between the indoor environmental conditions and the thermal stress of the animals through more accurate analysis that may involve the monitoring of physiological parameters, such as the cortisol level.
This work has been supported by financial funding of SIR (Scientific Independence of young Researchers) 2014 "EPAnHaus - Energy Performance of livestock houses" project, grant number RBSI141A3A, funded by MIUR (Italian Ministry of Education, Universities and Research).

Authors would like to thank Azienda Agricola S. Bernardo Colombé $(\mathrm{Bra}-\mathrm{CN}$ - Italy) for providing the test sites of this project.

Authors would like to thank ARPA Piemonte for sharing the outdoor weather data used in this work.

\section{References}

1. J.A. Lindley, J.H. Whitaker, Agricultural Buildings and Structures, ASAE (1996)

2. MWPS, Structures and Environment Handbook, MWPS (1983)

3. M.E. Esmay, J.E. Dixon, Environmental Control for Agricultural Buildings, The AVI Publishig company Inc. (1986)

4. N.R. St-Pierre, B. Cobanov, G. Schnitkey, J. Dairy Sci. 86, E52-E77 (2003)

5. A. Costantino, E. Fabrizio, A. Ghiggini, M. Bariani, Energy Build 169, 110-126 (2018)

6. P. Panagakis, P. Axaopoulos, Biosyst Eng 99, 112-118 (2008)

7. A. Costantino, E. Fabrizio, A. Biglia, P. Cornale, L. Battaglini, Energy Procedia 101, 184-191 (2016)

8. E. Fabrizio, A. Costantino, L. Comba, P. Cornale, L. Battaglini, 2017 ASABE Annual Meeting, Paper number 1701480 (2017)

9. A. Costantino, L. Comba, A. Rolfo, P. Cornale, L. Battaglini, E. Fabrizio, Analysis of the Indoor Climate and Energy Uses in Two Pig Houses, Proceedings of 2018 AgEng Conference (2018)

10. B. Gompertz, Philosophical Transactions of the Royal Society of London 115 (1825)

11. P. Rossi, A. Gastaldo, P. Ferrari, Ricoveri, attrezzature e impianti per l'allevamento dei suini.Edizioni L'informatore Agrario. [in Italian]. (2004)

12. A. F. Harper, Virginia Cooperative Extension (2003) 
13.P. Panagakis, P. Axaopoulos, Biosystem Engineering 99 (2008)

14. H. Xin, J. D. Harmon, Agriculture and Environment Extension Publications 163 (1998) 